\title{
Ebola Virus Disease: A Challenge for Humans
}

\section{Saurabh Nimesh*}

Research Scholar, Department of Pharmaceutical Technology, Meerut Institute of Engineering and Technology, Meerut, (Uttar Pradesh), India *Corresponding Author: Saurabh Nimesh, Research Scholar, Department of Pharmaceutical Technology, Meerut Institute of Engineering and Technology, Meerut, (Uttar Pradesh), India.

Received: April 22, 2019; Published: June 20, 2019

DOI: $10.31080 /$ ASPS.2019.03.0317

\begin{abstract}
Ebola virus also known as Ebola haemorrhagic fever, is a severe, often fatal illness in humans. Ebola virus disease (EVD) is transmitted to people from wild animals and spreads in the human population through person to person transmission. These viruses cause a disease characterised by systemic viral replication, immune suppression, abnormal inflammatory responses, major fluid and electrolyte losses, and high mortality. The World Health Organization (WHO) reports 24 outbreaks, 28633 cases and 11315 deaths in the recent outbreak. Currently, no specific treatment is available of Ebola's affected patients depends only supportive care and symptomatic treatment.
\end{abstract}

Keywords: Clinical Trials; Deaths; Amiodarone; Z Mapp; Filoviridae

\section{Abbreviations}

EVD: Ebola Virus Disease; EBOV: Ebola Virus; SUDV: Sudan Ebola virus; MARV: Marburg Ebola Virus; RAVV: Ravn Ebola Virus; BDBV: Bundibugyo Ebola Virus; DRC: Democratic Republic of Congo; U.S.: United State; U.K.: United Kingdom; CFR: Case Fatality Ratio; WHO: World Health Organization; CDC: Centers for Disease Control and Prevention; U.S.FDA: United States Food and Drug Administration.

\section{Introduction}

Ebola is the name of a small river in the North West of the Democratic Republic of Congo where the Ebola virus was first identified in humans in 1976 in Zaire (Figure 1). Ebola virus disease is an acute, viral and fatal illness among humans. EVD is a disease caused by infection with one of the five Ebola virus species of the family Filoviridae [1-5]. Four species, namely Sudan Ebola virus, Zaire Ebola virus, Bundibugyo Ebola virus and Cote d'Ivoire Ebola virus are capable of human infection with fatal outcomes [6]. Ebola virus transmitted from wild animals to human and could spread from human to human. The first outbreak of EVD was reported in 1967 in the DRC resulting in 318 cases and $88 \%$ death rate. According to WHO, the 2014 to 2016 outbreak of EVD in West Africa was the largest since the discovery of the
Ebola virus in 1976 [7-9]. More than 28000 cases and 11000 deaths were reported from the 3-disaster affected mainly Sierra Leone, Liberia and Guinea in West Africa. The number of cases and deaths, geographical distribution, social and political impact, and duration of the epidemic have created a global public health crisis. The disease course of EVD is rapid. After about one-week incubation period, victims rapidly develop a high fever, diarrhea, vomiting, respiratory disorders, haemorrhaging and death ensues within a few days. Its exact aetiology was unknown, and there are no approved specific treatment or vaccine for the therapy of EVD. Ebola's affected patient dependent on the maintenance of intravascular fluid volume of the patients and palliative care, even though some tested compounds exhibit promising antiviral activities against the Ebola virus [10-12]. A worldwide effort has been made to develop new therapeutic strategies, several of which were potential vaccines where promising results were demonstrated in non-human primates. Medical volunteers from U.S., Cuba, India, China and many other places around the world travelled to West Africa to support efforts to control the spread of the disease and care for patients, the vast majority of whom had never seen a case of Ebola or encountered such a devastating disease $[13,14]$. 


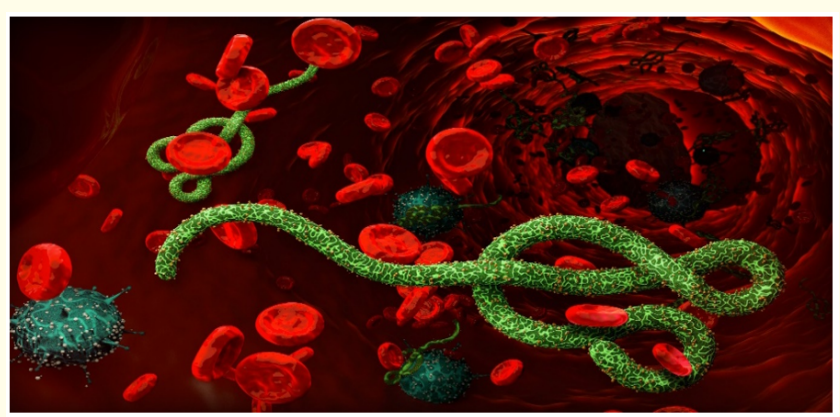

Figure 1: An electron micrograph of Ebola virus, obtained on 13 October 1976 at the CDC.

\section{Transmission of Virus}

There have been no cases of sexual transmission; and the life cycle of Ebola virus and its mode of entry to the human body is unknown.

1. Ebola virus get transmitted through direct contact with the bodily fluids of an infected wild animal or human [15].

2. These include blood, saliva, sweat, semen, vomit, urine or faeces.

3. The urine can also be contracted by handling a sick or dead wild animal previously infected. Later on, this can be transmitted from human to human (Figure 2) [16].

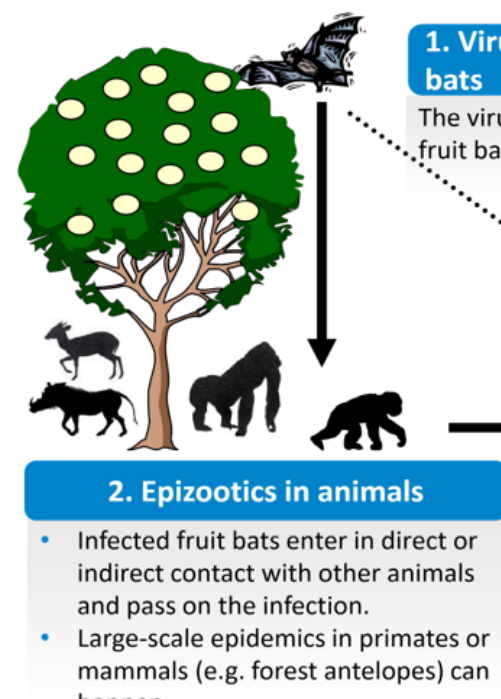

happen.
3. Primary human transmission

Humans are infected either through:

- handling infected dead or sick animals found in the forest (more frequent);

- or through direct contact with infected bats (rare event).

\section{Virus persistence}

Persistence of Ebola virus in body

fluids of EVD survivors represent

a risk for sexual transmission.

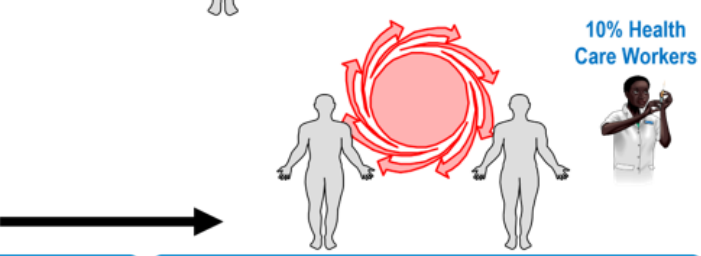

4. Secondary human transmission

- Secondary human-to-human transmission occurs through direct contact with the blood, secretions, organs or other body fluids of infected persons.

- High transmission risk when providing direct patient care or handling dead bodies (funerals).

Figure 2: Transmission of Ebola virus.

\section{Epidemiology of virus}

The first occurrence of the virus was recorded in the DRC. In West Africa, it was reported that the fatality rate of EVD was $90 \%$ in the 2013 outbreak [17]. This was an international public health emergency since there were 5740 cases in Guinea, 9890 in Liberia and 5000 in Sierra Leone as of 2 November 2014 [18]. There has been a big change in the epidemiology of EVD in the countries affected since the most recent outbreak (Table 1,2) [19-21]. A high number of cases are still being reported, most notably from the metropolitan areas of Katwa health zone during the past week. Trends in the number of new cases occurring in DRC health zones January to February 2019 (Figure 3,4 and 5) [22-26].

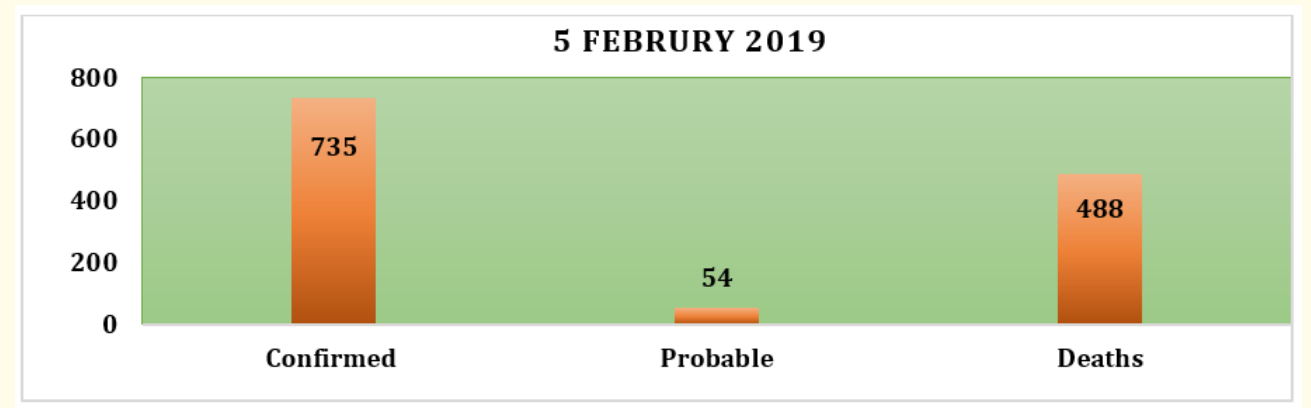

Figure 3: During the last 21 days (16 Jan to 5 Feb 2019) total 789 EVD cases, overall 488 deaths (CFR 62\%). 


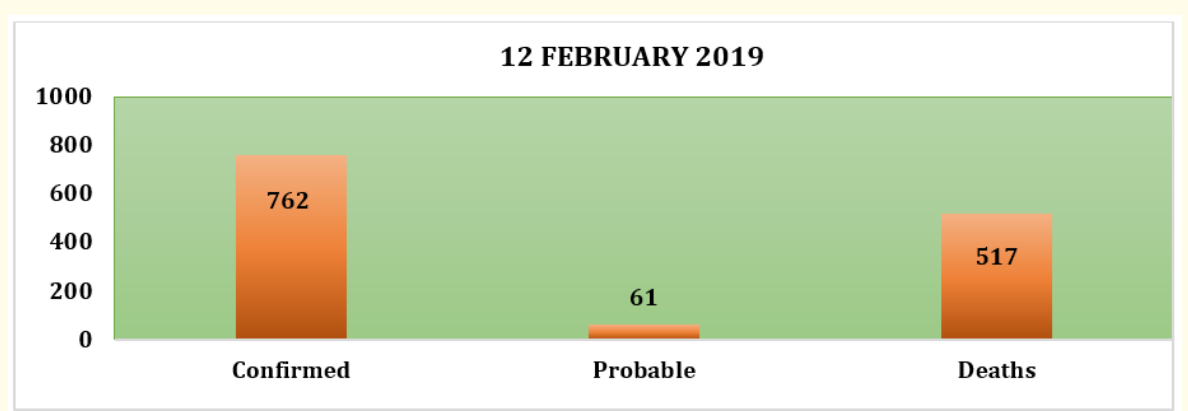

Figure 4: During the last 21 days (23 Jan to 12 Feb 2019) total 823 EVD cases, overall 517 deaths (CFR 63\%).

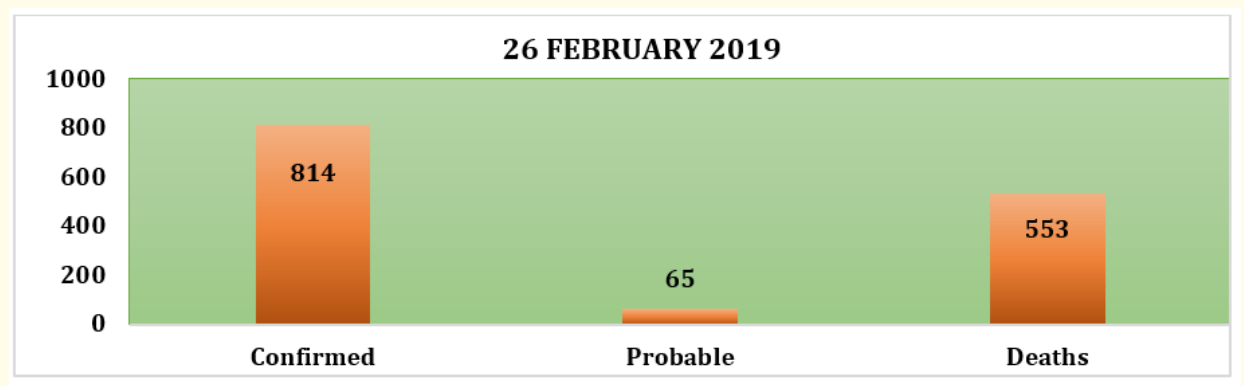

Figure 5: During the last 21 days (6 Feb to 26 Feb 2019) total 879 EVD cases, overall 553 deaths (CFR 63\%).

\begin{tabular}{|c|c|c|c|c|c|}
\hline Month-year & Country & Virus & Cases & Deaths & CFR \\
\hline Jun-Nov 1976 & Sudan & SUDV & 284 & 151 & $53 \%$ \\
\hline Aug 1976 & Zaire & EBOV & 318 & 280 & $88 \%$ \\
\hline Aug-Sep 1979 & Sudan & SUDV & 34 & 22 & $65 \%$ \\
\hline Dec 1994; Feb 1995 & Gabon & EBOV & 52 & 31 & $60 \%$ \\
\hline May-Jul 1995 & Zaire & EBOV & 315 & 254 & $81 \%$ \\
\hline Jan-Apr 1996 & Gabon & EBOV & 37 & 21 & $57 \%$ \\
\hline Jul 1996; Mar 1997 & Gabon & EBOV & 60 & 45 & $75 \%$ \\
\hline Oct 2000; Jan 2001 & Uganda & SUDV & 425 & 224 & $53 \%$ \\
\hline Oct 2001; Jul 2002 & Gabon; Republic of the Congo & EBOV & 135 & 107 & $79 \%$ \\
\hline Dec 2002; Apr 2003 & Republic of the Congo & EBOV & 143 & 128 & $90 \%$ \\
\hline Nov-Dec 2003 & Republic of the Congo & EBOV & 35 & 29 & $83 \%$ \\
\hline Apr-Jun 2004 & Sudan & SUDV & 17 & 7 & $41 \%$ \\
\hline Aug-Nov 2007 & DRC & EBOV & 264 & 187 & $71 \%$ \\
\hline Dec 2007; Jan 2008 & Uganda & BDBV & 149 & 37 & $25 \%$ \\
\hline Dec 2008; Feb 2009 & DRC & EBOV & 32 & 14 & $45 \%$ \\
\hline Jun-Aug 2012 & Uganda & SUDV & 24 & 17 & $71 \%$ \\
\hline Jun-Nov 2012 & DRC & BDBV & 77 & 36 & $47 \%$ \\
\hline Dec 2013; Jan 2016 & $\begin{array}{c}\text { Widespread: Liberia; Sierra; Leone and Guinea } \\
\text { Limited and local: Nigeria; Mali; U.S.; Senegal; Spain; } \\
\text { U.K. and Italy }\end{array}$ & EBOV & 28616 & 11310 & $\begin{array}{c}\text { 70-71\% general; } \\
\text { 57-59\% among } \\
\text { hospitalized patients }\end{array}$ \\
\hline Aug-Nov 2014 & DRC & EBOV & 66 & 49 & $74 \%$ \\
\hline May-Jul 2018 & DRC & EBOV & 54 & 33 & $61 \%$ \\
\hline August 2018- present & DRC & EBOV & 1112 & 582 & ongoing \\
\hline
\end{tabular}

Table 1: List of Ebola virus disease (major or massive) outbreaks. 


\begin{tabular}{|l|l|c|c|c|c|}
\hline Year & Country & Virus & Cases & Deaths & CFR \\
\hline 1967 & West Germany, Yugoslavia & MARV & 31 & 7 & $23 \%$ \\
\hline 1975 & Rhodesia, South Africa & MARV & 3 & 1 & $33 \%$ \\
\hline 1980 & Kenya & MARV & 2 & 1 & $50 \%$ \\
\hline 1987 & Kenya & RAVV & 1 & 1 & $100 \%$ \\
\hline 1990 & Soviet Union & MARV & 1 & 1 & $100 \%$ \\
\hline $1998-2000$ & DRC & MARV, RAVV & 154 & 128 & $83 \%$ \\
\hline $2004-2005$ & Angola & MARV & 252 & 227 & $90 \%$ \\
\hline 2007 & Uganda & MARV; RAVV & 4 & 1 & $25 \%$ \\
\hline 2008 & Uganda; Netherlands and U.S. & MARV & 2 & 1 & $50 \%$ \\
\hline 2012 & Uganda & MARV & 15 & 4 & $27 \%$ \\
\hline 2014 & Uganda & MARV & 1 & 1 & $100 \%$ \\
\hline 2017 & Uganda & MARV & 3 & 3 & $100 \%$ \\
\hline
\end{tabular}

Table 2: List of other Filoviridae outbreaks.

\section{Symptoms of virus}

Symptoms may appear anywhere from 2 to 21 days after contact with the virus, with an average of 8 to 10 days. Many common illnesses can have these same symptoms, including influenza (flu) or malaria [27]. First symptoms are the sudden onset of fever fatigue, muscle pain, headache and sore throat (Figure 6). This is followed by vomiting, diarrhea, skin rash, symptoms of impaired kidney and liver function, and in some cases, both internal and external bleeding (e.g. oozing from the gums, blood in the stools). Laboratory findings include low white blood cell and platelet counts and elevated liver enzymes [28].

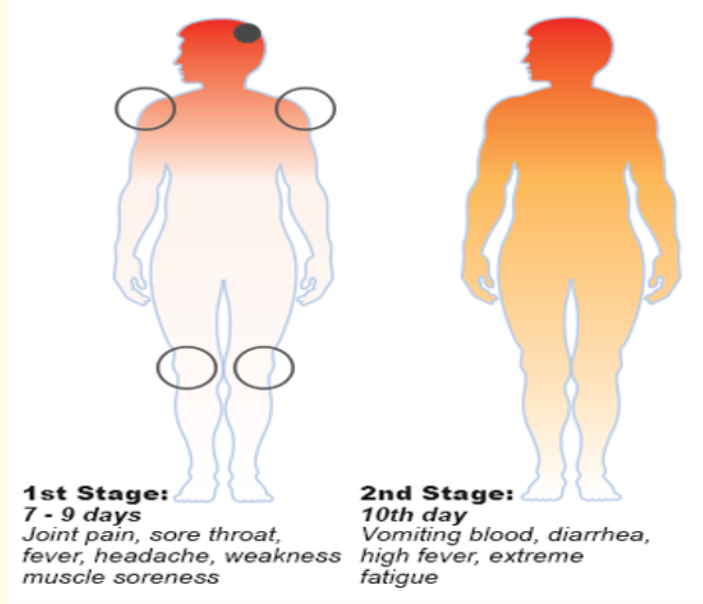

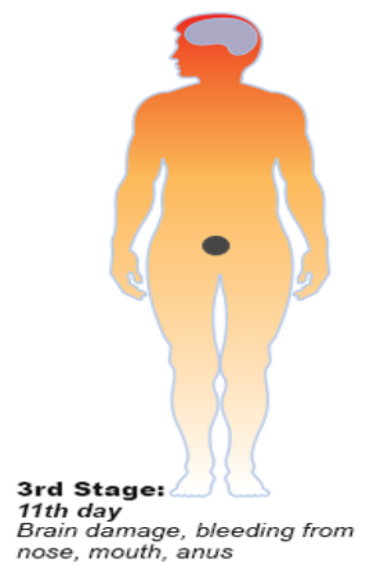

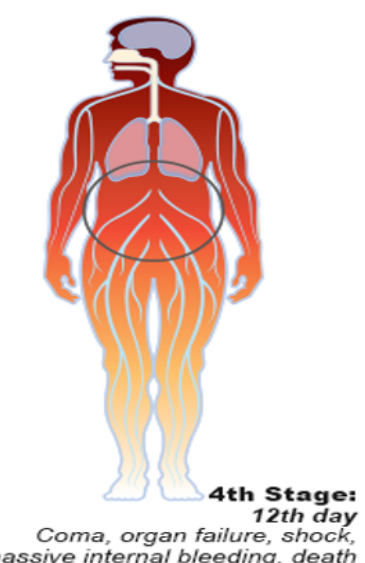

Coma, organ failure, shock,
massive internal bleeding, death

Figure 6: Occur 2 to 21 days after exposure, but 8 to 10 days is most common. 
Prevention and control of virus

1. Regular hand washing after handling patients.

2. Using protective gloves, wearing facial masks in vicinity of Ebola patients.

3. Use personal protective equipment's and proper sterilization of equipment's.

4. Early detection/contract tracing/isolation [29].
5. Burial of the dead-people who have died from Ebola should be promptly and safely buried.

6. Screening travelers from affected countries from EVD [30].

7. Public awareness from EVD and health messages should focus on reducing the risk of pig to human transmission as a result of unsafe animal husbandry and slaughtering practices, and unsafe consumption of fresh blood, raw milk or animal tissue (Figure 7) [31].

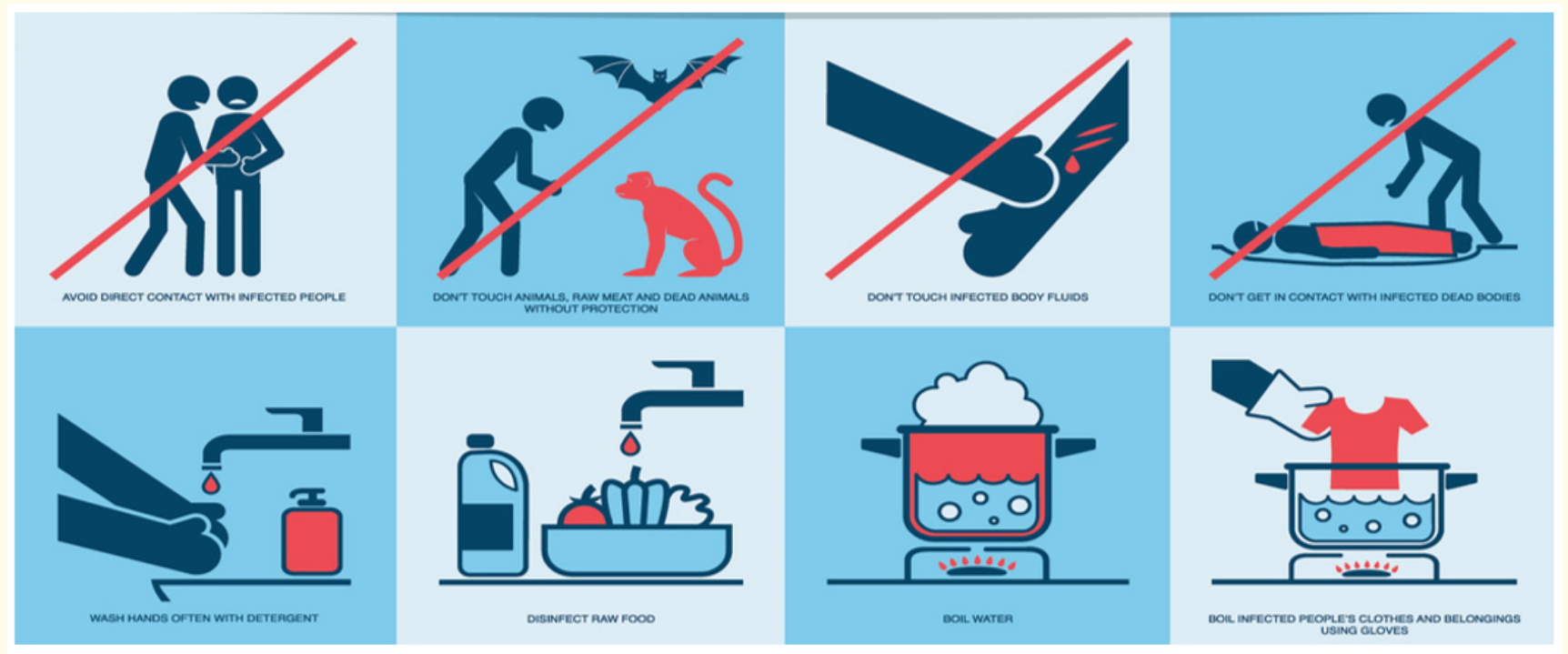

Figure 7: Prevention and control.

Treatment of virus

According to U.S. FDA currently, there is no licensed vaccine available for the treatment of EVD. Treatment against EVD mainly consist of providing medical care based on symptomatic therapy to maintain the vital respiratory, cardiovascular and renal functions (Table 3). However, a range of potential treatments including blood products, antibodies, immune therapies and drug therapies are currently being evaluated in clinical trials (Table 4) [32,33].

\begin{tabular}{|l|c|c|}
\hline S. No. & Condition & Recommended care \\
\hline 1 & Concomitant infections & $\begin{array}{c}\text { Broad spectrum antibiotics, empirical systematic malaria treatment in } \\
\text { malaria-endemic areas }\end{array}$ \\
\hline 2 & Nausea or vomiting & Antiemetic drugs (metoclopramide, ondansetron and haloperidol) \\
\hline 3 & Severe pain & Opiates \\
\hline 4 & Palliative care & Opiates \\
\hline 5 & Mild to moderate pain & Paracetamol \\
\hline 6 & Critical ill patients & Oral feeding wherever possible, enteral feeding \\
\hline 7 & Hypoxaemia & Oxygen therapy \\
\hline 8 & Encephalitis/encephalopathy & Opiates for symptomatic management \\
\hline
\end{tabular}

Table 3: Symptomatic therapy for Ebola virus disease. 


\begin{tabular}{|c|l|l|}
\hline S. No. & Vaccines and antibodies therapy & Company/country origin \\
\hline 1 & cAd3 & GlaxoSmithKline, Brentford (London) \\
\hline 2 & rVSV & National Microbiology Laboratory in Winnipeg, Manitoba (Canada) \\
\hline 3 & Favipiravir (T-705) & Toyama chemicals, Tokyo (Japan) \\
\hline 4 & Z Mapp & MappBio, San Diego, CA, (United States of America) \\
\hline 5 & TKM-130803 (TKM) & Arbutus Biopharma, formerly Tekmira Pharmaceuticals, Burnaby (Canada) \\
\hline 6 & mAb114 & Ridgeback Biotherapeutics LP., Biotechnology company, Miami, (Florida) \\
\hline 7 & Galidesivir (BCX4430, Immucillin-A) & $\begin{array}{l}\text { BioCryst Pharmaceuticals, Inc., Pharmaceutical company, Durham, North Carolina } \\
\text { (United States) }\end{array}$ \\
\hline 8 & Triazavirin (TZV) & Ural Center for Biopharma Technologies and Medsintez Pharmaceutical (Russia) \\
\hline 9 & MK-608 & Merck \& Co., Inc, American pharmaceutical company \\
\hline
\end{tabular}

Table 4: Therapeutics evaluation in clinical trials of vaccines and antibodies in EVD.

\section{Conclusion}

Ebola virus disease or Ebola haemorrhagic fever is caused by Ebola viruses. Disease has high mortality and no specific treatment or vaccine. Diagnosis by detection of viral RNA, viral antibodies or virus itself. Treatment is mainly supportive in nature. This article can be used as a basis for further research that could be conducted to explore the knowledge of EVD among healthcare professionals in other parts of the world.

\section{Acknowledgements}

Author would like to thanks to Mr. Ravi Tomar, Manoj Kumar, NitishTyagi and Peeyush Kumar Shukla of B. Pharm final year students of Meerut Institute of Engineering and Technology Meerut (Uttar Pradesh), India; for her support and helpful in cooperation in the data collection process.

\section{Conflict of Interest}

The Author declare that there is no conflict of interest.

\section{Bibliography}

1. Salami K K., et al. "Ebola outbreak in Nigeria: perceptions from commercial motorcyclists and passengers in Ibadan, Nigeria". Health Education Research 34.1 (2019): 1-14.

2. Malvy D., et al. "Ebola virus disease". Lancet 393 (2019): 936948.
3. Marzi A., et al. "Recently identified mutations in the Ebola virus-makona genome do not alter pathogenicity in animal models". Cell Reports 23.6 (2018): 1806-1816.

4. Mbala K P., et al. "Rapid confirmation of the Zaire Ebola virus in the outbreak of the Equateur province in the Democratic Republic of Congo: implications for public health interventions". Clinical Infectious Diseases 68.2 (2019): 330-333.

5. Ebola Outbreak Epidemiology Team. "Outbreak of Ebola virus disease in the Democratic Republic of the Congo, April-May, 2018: an epidemiological study". Lancet 392.10143 (2018): 213-221.

6. Emanuel J., et al. "Filoviruses: ecology, molecular biology, and evolution". Advances in Virus Research 100 (2018): 189-221.

7. Chu D K., et al. "Mortality and morbidity in acutely ill adults treated with liberal versus conservative oxygen therapy (IOTA): a systematic review and meta-analysis". Lancet 391.10131 (2018): 1693-1705.

8. Lamontagne F., et al. "Evidence-based guidelines for supportive care of patients with Ebola virus disease". Lancet 391.10121 (2018): 700-778.

9. Collet M O., et al. "Prevalence and risk factors related to haloperidol use for delirium in adult intensive care patients: the multinational AID-ICU inception cohort study". Intensive Care Medicine 44.7 (2018):1081-1089. 
10. Sivapalasingam S., et al. "Safety, pharmacokinetics, and immunogenicity of a co-formulated cocktail of three human monoclonal antibodies targeting Ebola virus glycoprotein in healthy adults: a randomised, first-in-human phase 1 study". The Lancet Infectious Diseases 18 (2018): 884-893.

11. Howlett P J., et al. "Case series of severe neurologic sequelae of Ebola virus disease during epidemic, Sierra Leone". Emerging Infectious Diseases 24.8 (2018): 1412-1421.

12. Thomalla G., et al. "MRI-guided thrombolysis for stroke with unknown time of onset". New England Journal of Medicine 379 (2018): 611-622.

13. Albers G W., et al. "Thrombectomy for stroke at 6 to 16 hours with selection by perfusion imaging". New England Journal of Medicine 378 (2018): 708-718.

14. Nogueira R G., et al. "Thrombectomy 6 to 24 hours after stroke with a mismatch between deficit and infarct". New England Journal of Medicine 378 (2018): 11-21.

15. WHO. "Ebola virus disease Democratic Republic of the Congo. External situation report”. World Health Organization Regional Office for Africa (2019).

16. Dokubo E K., et al. "Persistence of Ebola virus after the end of widespread transmission in Liberia: an outbreak report". Lancet Infectious Diseases 18.9 (2018): 1015-1024.

17. Boon S D., et al. "Ebola Virus Infection Associated with Transmission from Survivors". Emerging Infectious Diseases 25.2 (2019): 240-246.

18. WHO. "Health worker Ebola infections in Guinea, Liberia and Sierra Leone". Preliminary report (2015).

19. WHO. "Ebola virus disease-Democratic Republic of the Congo". Disease outbreak news (2018).

20. Centers for Disease Prevention and Control. "Years of Ebola virus disease outbreaks". Atlanta: CDC (2018).

21. World Health Organization. "Ebola virus disease - fact sheet [Internet]". Geneva: WHO (2018).

22. Lamontagne F., et al. "Evidence-based guidelines for supportive care of patients with Ebola virus disease". Lancet 391.10121 (2018): 700-708.

23. To K K., et al. "Ebola virus disease: a highly fatal infectious disease re-emerging in West Africa". Microbes and Infection 17.2 (2015): 84-97.
24. Tseng C P and Chan Y J. "Overview of Ebola virus disease in 2014". Journal of the Chinese Medical Association 78.1 (2015): 51-55.

25. "Ebola: Mapping the outbreak". BBC news (2016).

26. Centre of Disease Control and Prevention. "About Ebola virus disease". (2016).

27. Olupot-Olupot P. "Ebola in children: epidemiology, clinical features, diagnosis and outcomes". Pediatric Infectious Disease Journal 34.3 (2015): 314-316.

28. Park D J., et al. "Ebola virus epidemiology, transmission, and evolution during seven months in Sierra Leone". Cell 161.7 (2015): 1516-1526.

29. van Griensven J., et al. "Evaluation of convalescent plasma for Ebola virus disease in Guinea". New England Journal of Medicine 374 (2016): 33-42.

30. Moon S., et al. "Will Ebola change the game? Ten essential reforms before the next pandemic. The report of the HarvardLSHTM Independent Panel on the Global Response to Ebola". Lancet 386 (2015): 2204-2221.

31. Plucinski M M., et al. "Effect of the Ebola-virus-disease epidemic on malaria case management in Guinea, 2014 a crosssectional survey of health facilities". Lancet Infectious Diseases 15.9 (2015): 1017-1023.

32. Murphy F A. "Historical perspective: what constitutes discovery (of a new virus)? In: Kielian M, Maramorosch K, Mettenleiter TC, eds. Advances in virus research". Amsterdam: Elsevier 95 (2016): 197-220.

33. Sands P., et al. "The neglected dimension of global security - a framework for countering infectious-disease crises". New England Journal of Medicine 374 (2016):1281-1287.

\section{Volume 3 Issue 7 July 2019}

(c) All rights are reserved by Saurabh Nimesh. 